\title{
DETECCIÓN Y AISLAMIENTO DE MICROORGANISMOS EXOELECTRÓGENOS A PARTIR DE LODOS DEL RÍO LERMA, ESTADO DE MÉXICO, MÉXICO
}

\author{
Jorge Humberto SERMENT GUERRERO ${ }^{1 *}$, Eric Arturo LARA RIVERA ${ }^{1}$, Karina BECERRIL VARELA ${ }^{1}$, \\ Sergio SUÁREZ CONTRERAS ${ }^{1}$ y Ninfa RAMÍREZ DURÁN ${ }^{2}$
}

${ }^{1}$ Instituto Nacional de Investigaciones Nucleares. Carretera México-Toluca, kilómetro 36.5, La Marquesa, Municipio de Ocoyoacac, Estado de México, C. P. 52750

${ }^{2}$ Facultad de Medicina, Universidad Autónoma del Estado de México. Paseo Colón esquina con Paseo Tollocan, Toluca, Estado de México, C. P. 50100

*Autor para correspondencia: jorge.serment@inin.gob.mx

(Recibido abril 2016; aceptado marzo 2017)

Palabras clave: bacterias exoelectrógenas, celdas de energía microbiana

\section{RESUMEN}

Algunos microorganismos, como las bacterias, son capaces de producir energía renovable sin daño al ambiente. Las celdas de energía microbiana ofrecen la posibilidad de convertir compuestos orgánicos en electricidad mediante el metabolismo de dichos microorganismos al crear subproductos, entre los que están diferentes iones que son liberados hacia el medio extracelular. En estos dispositivos se coloca un electrodo como aceptor final para captar los electrones que liberan los microorganismos al degradar la materia orgánica. A la fecha se conocen varios microorganismos con la capacidad de liberar electrones a través del metabolismo, sin embargo son pocos los que pueden realizarlo sin la presencia de mediadores, por lo que es importante continuar con la búsqueda e identificación de estos organismos. En el presente trabajo se utilizaron dos diferentes celdas de energía microbiana para optimizar el proceso de aislamiento de bacterias exoelectrógenas a partir de lodos del río Lerma y de la planta de tratamiento de agua del Centro Interamericano de Recursos del Agua. Se comparó la generación de voltaje de estos microorganismos exoelectrógenos con la de Geobacter sulfurreducens, que es una de las bacterias de este tipo más eficaces. En conjunto los datos obtenidos indican que, aunque no son tan eficientes como G. sulfurreducens, las bacterias aisladas en el Instituto Nacional de Investigaciones Nucleares (identificadas mediante ARN ribosomal como Clostridium sordellii y C. bifermentans), presentan una buena generación de voltaje. Los resultados muestran que la estrategia planteada en este trabajo es adecuada para la localización, aislamiento e identificación de bacterias exoelectrógenas que pudieran ser utilizadas in situ para tratamiento y generación de electricidad en zonas contaminadas.

Key words: exoelectrogen bacteria, microbial fuel cells

\begin{abstract}
Some microorganisms (such as bacteria) are capable of producing renewable energy without harassing the environment. Microbial fuel cells (MFC) offer the possibility of transforming organic matter into electricity by using the metabolism of
\end{abstract}


these microorganisms, creating ions within the subproducts of the metabolism that go to the extracellular environment. An electrode is set into the MFC that works as a final acceptor that attracts the electrons released by the microorganisms after consuming organic matter. To date, many microorganisms with the capability of liberating electrons through their metabolism have been identified. However only few are able of doing so without chemical mediators, which is why the search of new exoelectrogen microorganisms is of great importance. On the present work, two different MFC were employed for optimizing the isolation of exoelectrogenic bacteria gathered from mud of the Lerma river and from the Centro Interamericano de Recursos del Agua water treatment plant. Voltage generated by these microorganisms was compared with that created by Geobacter sulfurrenducens, one of the most efficient bacteria in this field. Overall, the obtained data show that the isolated bacteria at the National Institute of Nuclear Research facilities (identified by ribosomal RNA as Clostridium sordellii and C. bifermentans) have a good voltage generation, although not as good as the one from G. sulfurrenducens. Results indicate that the strategy employed in the research is suitable for efficiently locating, isolating and identifying exoelectrogenic bacteria that may be used later on for the in situ generation of electricity in polluted areas.

\section{INTRODUCCIÓN}

En los últimos 20 años el crecimiento económico de los países desarrollados ha estado determinado en gran medida por la explotación de combustibles fósiles cuyo consumo ha ido aumentando significativamente debido al rápido crecimiento económico y poblacional. El consumo de energía en el mundo en 2001 fue de 13.5 a 27 TeraWatts (TW) y se ha proyectado que para el 2100 será de 43 TW (Lewis y Nocera 2006). Esto supone que el consumo de combustibles como el petróleo crudo, gas natural y biocombustibles se incrementará en los años siguientes, lo que a su vez acentuará los efectos antrópicos sobre el cambio climático, por lo que se espera que la implementación de energías renovables sea una alternativa real en el futuro cercano (Estrada y Salazar 2013).

Hoy en día, en busca de alternativas para mejorar la calidad de vida, se contempla el uso de bacterias para muy diversos fines, dado que desde su origen han sido parte del desarrollo del planeta. Una de las problemáticas ambientales que se han presentado es la contaminación de ríos, lagos, mares, etc. que a lo largo del tiempo han ocasionado un daño considerable. Así, la biorremediación es una opción viable para el tratamiento de esas aguas ya que ayuda a la descontaminación y además es posible obtener un beneficio energético a partir de la degradación de la materia orgánica (Falcón et al. 2009). El uso y aislamiento de microorganismos nativos ofrecen una gran variedad de aplicaciones para la biorremediación de sitios contaminados. Esto es debido a que ya han sido sometidos a descargas de contaminantes, lo que hizo que desarrollaran resistencia a diferentes agentes tóxicos, transformando estos en sustancias inocuas para el ambiente (Benavides et al. 2006, Marzan et al. 2017). La conversión de energía química en eléctrica es una alternativa que ha despertado interés en los últimos años y los microorganismos, como las bacterias, son capaces de llevar a cabo esto sin dañar al ambiente (He et al. 2005). En los sedimentos de ríos o lagunas se generan condiciones anóxicas que permiten el desarrollo de bacterias con metabolismo anaerobio. Bajo estas condiciones, las bacterias utilizan como fuentes de carbono y donadores de hidrógeno los compuestos producidos por las bacterias fermentadoras. Al degradar estos productos se desprenden electrones liberados que terminan acoplándose a compuestos como el nitrato, el sulfato, y el Fe (III), entre otros (Esteve-Núñez et al. 2008). En los últimos años han tomado auge las llamadas celdas de energía microbiana (CEM) (Logan et al. 2006), que transforman un sustrato biodegradable directamente en electricidad, con lo que se liberan electrones, protones y $\mathrm{CO}_{2}$. Los iones provienen de donadores como acetato o glucosa y una vez que están libres en la célula bacteriana ésta pone en función cadenas de transporte de electrones que actúan como agentes oxidantes o reductores. De este sistema de transporte, parte de los electrones y protones se liberan fuera de la célula gracias a proteínas y filamentos presentes en la membrana de la bacteria. Es posible añadir sustancias con propiedades reductoras oxidativas (redox) que actúan como mediadores para incrementar este transporte. Sin embargo su uso tiene limitantes ya que incrementa los costos y son también sustancias contaminantes. Los electrones son atraídos por el ánodo (que se encuentra en condiciones anaerobias) 
y de aquí viajan por un circuito externo que los conduce a través de una resistencia de valor conocido colocada externamente para después llegar al cátodo (condiciones aerobias), donde entran en contacto con los protones que migraron de la cámara anódica a la catódica a través de una barrera que permite el intercambio catiónico. Comúnmente se usa oxígeno como aceptor de electrones debido a su potencial de oxidación, disponibilidad y sustentabilidad, además de no producir desechos químicos ya que se forma agua como único producto.

Si bien ya han sido reportadas diversas especies bacterianas como generadoras de electricidad, aún hay varios estudios por realizar en este campo, además de que los trabajos de biorremediación son más eficientes si se utilizan bacterias aisladas en el sitio a depurar. En este trabajo se reporta el uso de dos tipos de CEM para el aislamiento y caracterización de bacterias exoelectrógenas colectadas directamente de lodos del río Lerma, Estado de México y de la planta de tratamiento de agua del Centro Interamericano de Recursos del Agua (CIRA).

\section{MATERIALES Y MÉTODOS}

\section{Elección del sitio de muestreo}

Para este trabajo se hizo un sólo muestreo en el que se colectaron tres muestras de los sedimentos del río Lerma. Dos de ellas se tomaron en las cercanías de la planta tratadora Reciclagua (altitud 2583 msnm, latitud N: $19^{\circ} 17^{\prime} 10.3^{\prime}$, longitud. O: $99^{\circ} 31^{\prime}$ 18.0"), mientras que la tercer muestra se tomó de sedimentos cercanos a la Planta Tratadora Norte de Toluca (altitud $2585 \mathrm{msnm}$, latitud N: $19^{\circ} 23$ '21.5 ", longitud O: $\left.99^{\circ} 34^{\prime} 30.9^{\prime \prime}\right)$. Estas muestras se identificaron como Lerma (ML) I, II y III, respectivamente. Una cuarta y última muestra se obtuvo del lodo proveniente del reactor anaerobio de la planta de tratamiento del CIRA y se identificó con estas siglas.

\section{Toma y preservación de la muestra}

Para la extracción de las muestras del río Lerma se empleó una draga de tipo cuchara que se esterilizó con alcohol al $70 \%$, previo a la toma de cada muestra. De cada muestra extraída se tomó $0.1 \mathrm{~mL}$ con la ayuda de una jeringa, mismos que se inyectaron en tubos Hungate con medio de cultivo anaerobio. El resto de la muestra se transfirió a bolsas estériles, las que se etiquetaron, sellaron y conservaron en hielo para el transporte. Una vez en el laboratorio se congelaron a $-20^{\circ} \mathrm{C}$ para su preservación. Los tubos Hungate se incubaron a $30^{\circ} \mathrm{C}$.

\section{Detección de potencial eléctrico en las muestras}

Para la detección del potencial eléctrico en las muestras fue necesaria la construcción de una celda de energía microbiana. Se construyeron celdas de tipo $\mathrm{H}$, formadas por dos tubos de $30 \mathrm{~mm}$ de diámetro (cámara aerobia y anaerobia), con una capacidad de 65 a $70 \mathrm{~cm}^{3}$ cada cámara. Las cámaras se comunicaron entre sí por medio de un tubo de vidrio hueco de $0.7 \mathrm{~mm}$ de diámetro y con una longitud de $8 \mathrm{~cm}$ (Fig. 1). Como electrodos se decidió utilizar una lámina de acero inoxidable con una superficie de $8 \mathrm{~cm}^{2}$ unida a una varilla del mismo material, acoplada a un tapón de neopreno para mantener sellada la cámara anaerobia. Mientras que en la cámara aerobia se colocó un tapón de algodón para favorecer su aireación pasiva.

Se vertió un puente salino con agar bacteriológico (Bioxon 215000) y un amortiguador de fosfatos a $\mathrm{pH}$ 7.0 (PBS) al fondo de la celda para comunicar a las dos cámaras y que funcionara como puente de intercambio de protones. En la cámara anaerobia se vertió el medio de cultivo Ravot (Ravot et al. 1995) y se inoculó con una alícuota de $0.1 \mathrm{~mL}$ de la muestra de microorganismos correspondiente. Todo lo anterior se realizó en ambiente anóxico dentro de la cámara de guantes, la cual se purgó previamente con nitrógeno.

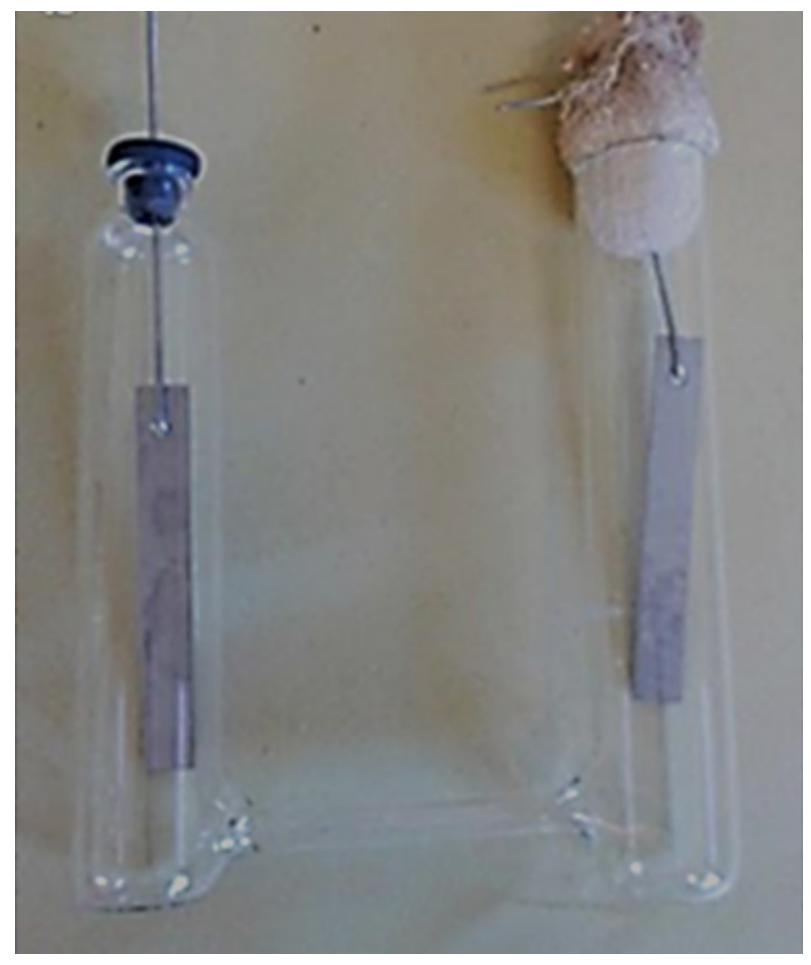

Fig. 1. Celda tipo H fabricada en el Instituto Nacional de Investigaciones Nucleares. Se puede ver el tubo de vidrio que une a los tubos de ensaye. Como electrodos se utilizó acero inoxidable 
Posteriormente las celdas se incubaron a $30{ }^{\circ} \mathrm{C}$ y se monitoreó el voltaje con un multímetro convencional marca Fluke modelo 117. Cabe mencionar que los experimentos se realizaron por triplicado.

\section{Aislamiento de microorganismos anaerobios}

A partir de las muestras con los voltajes más altos se realizó el aislamiento de las colonias de microorganismos. Para ello se sembró cada muestra por estría en un tubo con medio Ravot sólido, con una serie de diluciones de $10^{-1}$ a $10^{-5}$ bajo condiciones anóxicas dentro de la caja de guantes que fue purgada previamente con nitrógeno. Una vez inoculados los tubos se colocaron en una jarra de anaerobiosis purgada con nitrógeno dentro de una incubadora a $30{ }^{\circ} \mathrm{C}$ hasta alcanzar el crecimiento de las colonias (10-15 días). Se realizó una selección visual de todas las colonias presentes con base en su morfología y color. Con un asa se tomó cada colonia y se sembró en medio Ravot. Cada colonia fue colocada en celdas tipo $\mathrm{H}$ con puente salino como se describió arriba para seleccionar aquellas con potencial eléctrico.

\section{Construcción de una CEM de dos cámaras en forma de cubo}

Una vez seleccionadas las bacterias con mejor potencial se decidió construir una CEM de dos cámaras en lotes en forma de cubo con la finalidad de incrementar la eficiencia en la producción de electricidad. El armado de cada celda se hizo con la unión de varias placas de acrílico para crear dos cubos que serían las cámaras anódica y catódica, cada una de éstas lleva en su cara interna una ventana circular que permite la comunicación entre ambas (Fig. 2a). Asimismo se perforaron dos puertos de muestreo en la parte superior de cada una (Fig. 2b). Finalmente en la cara externa de cada cámara se acopló una placa de acrílico de mayor tamaño, que permite cruzar pernos a través de ella para unir dichas cámaras a presión. El volumen total de cada cámara es de $110 \mathrm{~cm}^{3}$. Las cámaras se construyeron en el área de talleres del instituto Nacional de Investigaciones Nucleares.

Las celdas se esterilizaron al exponerlas a $1.5 \mathrm{kGy}$ de radiación gamma de Cobalto 60 en un irradiador industrial. Después se colocaron $100 \mathrm{~mL}$ de medio Ravot en la cámara del ánodo y $100 \mathrm{~mL}$ de agua desionizada estéril en la cámara del cátodo. Se utilizó en ambas cámaras tela de grafito (mod. PW06, Zoltek) como electrodo, con un área de $16 \mathrm{~cm}^{2}$ cada uno, acoplada a un alambre de acero inoxidable de $3.5 \mathrm{~cm}$ de longitud. Previo a su uso, la tela de grafito se sumergió en una solución $1 \mathrm{M}$ de $\mathrm{HCl}$ con
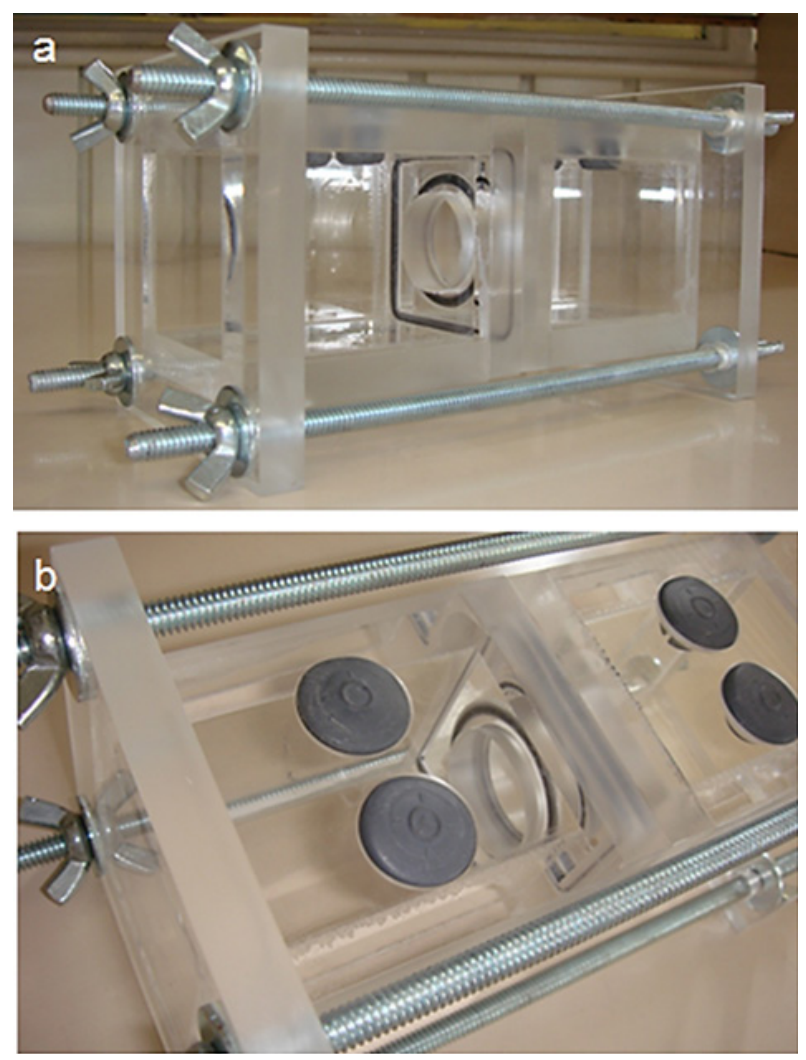

Fig. 2. Celda de energía microbiana en lote construida en el Instituto Nacional de Investigaciones Nucleares

agitación constante por una hora. Posteriormente se pasó a una solución $1 \mathrm{M}$ de $\mathrm{NaOH}$ donde se dejó por una hora con agitación constante con el fin de eliminar cualquier residuo orgánico. A continuación se enjuagó con agua bidestilada y se esterilizó en autoclave. Se utilizó una membrana de intercambio catiónico CIM-7000S (Membranes International) con una superficie de contacto de $5.31 \mathrm{~cm}^{2}$. La membrana se esterilizó en autoclave y luego se colocó en una solución de $\mathrm{NaCl}(2 \%)$ a $37^{\circ} \mathrm{C}$ por $2 \mathrm{~h}$ para permitir su expansión (Kim et al. 2008).

La oxigenación de la cámara catódica se realizó con una bomba de aire conectada a difusores de oxígeno de $2 \mathrm{~cm}$ de largo por $0.5 \mathrm{~cm}$ de ancho. Se inoculó la celda con $0.1 \mathrm{~mL}$ de cultivo de la bacteria aislada (todo esto se realizó en la cámara de guantes en un ambiente anóxico) y se incubó a una temperatura de $30^{\circ} \mathrm{C} \pm 0.2$.

\section{Microscopía electrónica de alto vacío}

Se prepararon las muestras de microorganismos de acuerdo con la técnica descrita por Vázquez-Nin y Echeverría (2000). Se transfirió $1 \mathrm{~mL}$ de un cultivo de bacterias en fase estacionaria a microtubos, se centrifugó por $30 \mathrm{~s}$ a $10000 \mathrm{Xg}$, se desechó el sobrenadante y se resuspendió el botón en $1 \mathrm{~mL}$ de una solución 
que contiene $7.6 \mathrm{~mL}$ de amortiguador de fosfatos $0.2 \mathrm{M} \mathrm{pH} 7.0$ y $2.4 \mathrm{~mL}$ de glutaraldehído al $25 \%$ y se dejó a temperatura ambiente por $2 \mathrm{~h}$. Transcurrido este tiempo se centrifugó por $30 \mathrm{~s}$ a $10000 \mathrm{X}$ g, se eliminó el sobrenadante, se lavó dos veces con $1 \mathrm{~mL}$ de amortiguador de fosfatos y finamente se agregó $0.1 \mathrm{~mL}$ de tetraóxido de osmio al $2 \%$ para cubrir la muestra. Se dejó por 12-24 h a temperatura ambiente dentro de la campana de extracción, se lavó dos veces con amortiguador de fosfatos y se realizó la deshidratación con etanol a diferentes concentraciones (10 min en etanol al 10\%, 30\%, 50\%, $70 \%$ y absoluto). Finalmente, se pasó la suspensión de bacterias por una membrana de policarbonato Millipore ${ }^{\circledR}$ con un diámetro de poro de $0.2 \mu \mathrm{m}$ y justo antes de verlas al microscopio se le aplicó un recubrimiento de oro para tener mejor contraste.

\section{Identificación de especies por análisis de secuen- ciación del ARN ribosomal $16 \mathrm{~S}$}

Para la obtención de biomasa las bacterias se inocularon en medio líquido Ravot y se incubaron a $30^{\circ} \mathrm{C}$ durante tres días en condiciones anaerobias. A las cepas aisladas se les realizó la extracción de ADN de acuerdo con el protocolo del paquete comercial Wi$\operatorname{zard}{ }^{\circledR}$ Genomic DNA Purification (Promega A1120).

Para la amplificación del ARN ribosomal 16S, se emplearon dos juegos de cebadores (primers, por su término en inglés) universales:

\section{7f 5'- AGAGTTTGATCMTGGCTCAG-3' 1492r: 5'- TACGGYTACCTT GTTACGACTT-3' 518f: 5'-CCAGCAGCCGCGGTAATACG-3' 800r: 5'-TACCAGGGTATCTAATCC-3'}

Para la reacción en cadena de la polimerasa (PCR, por sus siglas en inglés) se utilizó la polimerasa Taq marca Bioline ${ }^{\circledR}$ (BIO 21105). Las condiciones del ciclo térmico fueron: un ciclo de predesnaturalización por $5 \mathrm{~min}\left(94^{\circ} \mathrm{C}\right)$, desnaturalización $30 \mathrm{~s}\left(94^{\circ} \mathrm{C}\right)$, acoplamiento $20 \mathrm{~s}\left(52^{\circ} \mathrm{C}\right)$ y elongación $1: 30 \mathrm{~min}$ $\left(72^{\circ} \mathrm{C}\right)$. Estas condiciones se repitieron por 34 ciclos y posteriormente se dio un paso de post elongación de 7 min $\left(72^{\circ} \mathrm{C}\right)$. Los productos amplificados se purificaron con el paquete Amicon Ultra Filter (Millipore UFC901008) y se verificó su presencia y calidad en un gel de agarosa al $1 \%$. Los productos de la amplificación del ARN ribosomal 16S fueron enviados al servicio de secuenciación de Macrogen Sequenciation Service, Maryland, EUA. Las secuencias obtenidas se ensamblaron y corrigieron con el programa Cromas Pro version 1.5. Las secuencias obtenidas se compararon con las validadas y depositadas en las bases de datos del GenBank del National Center for Biotechnology Information (NCBI) por medio del programa Blast (Altschul et al. 1997, Zhang et al. 2000).

\section{RESULTADOS Y DISCUSIÓN}

\section{Evaluación del potencial eléctrico en las muestras}

Para determinar si las muestras colectadas tenían potencial eléctrico se midió la producción de algún voltaje con las celdas tipo $\mathrm{H}$ y si lo producían se registró con un multímetro convencional en circuito abierto por un periodo de 30 días. Las celdas tuvieron un incremento de voltaje en los primeros dos días (los valores más altos oscilan entre 0.40 y $0.47 \mathrm{~V}$ ) que se mantuvo durante los primeros cuatro a cinco días y después disminuyó paulatinamente (Fig. 3), probablemente debido al consumo de una buena parte de los donadores de electrones contenidos en el medio. Las muestras que obtuvieron los voltajes más altos y que los mantuvieron por más tiempo fueron ML-I y CIRA, mientras que ML-II y III tuvieron una caída notable hacia el día 22, para llegar a voltajes inferiores a $0.3 \mathrm{~V}$. La celda testigo (sin bacterias) también presentó un incremento de voltaje en los primeros días que se atribuye a la presencia de cargas en el medio, mismas que disminuyeron al no haber una reacción que liberara más a partir de los sustratos del entorno. Después del cuarto día la celda testigo fue disminuyendo su voltaje hasta valores de $0.010 \mathrm{~V}$, lo que permitió hacer un buen contraste entre las celdas inoculadas y el testigo.

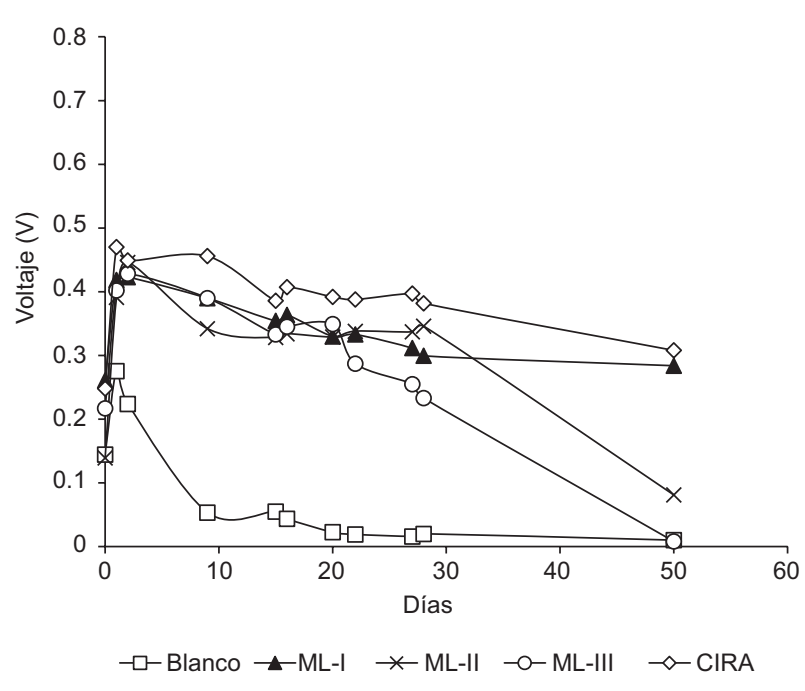

Fig. 3. Promedio del voltaje con respecto al tiempo en las diferentes muestras en celdas tipo $\mathrm{H}$. ML = muestra Lerma, CIRA $=$ muestra Centro Interamericano de Recursos del Agua 

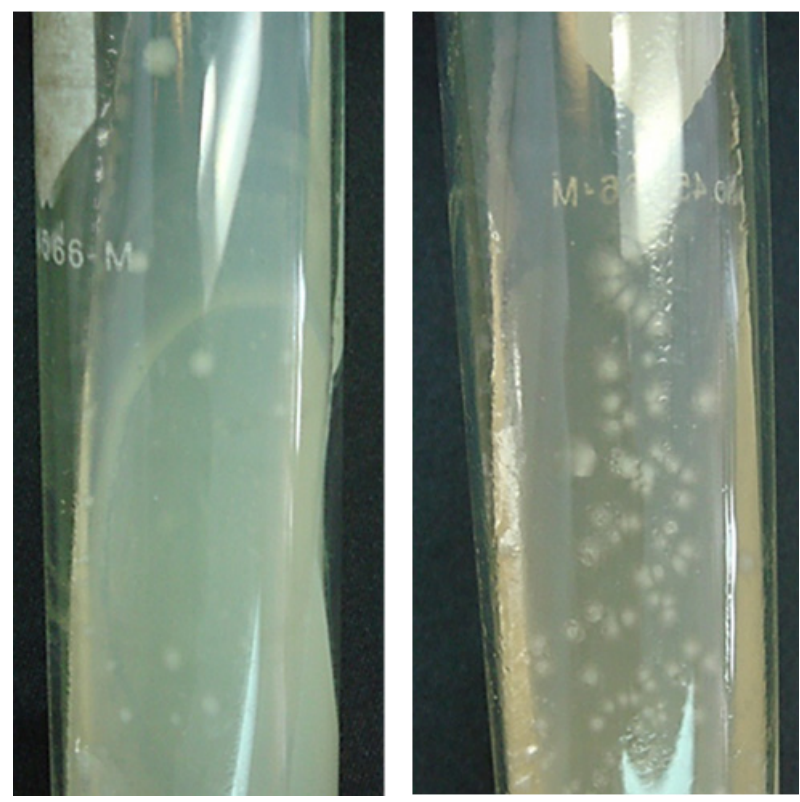

Fig. 4. Colonias aisladas obtenidas de las muestras de a) Lerma I y b) Centro Interamericano de Recursos del Agua. Se pueden apreciar diferentes morfologías de las colonias

\section{Aislamiento de colonias exoelectrógenas}

Las colonias de microorganismos con el mejor potencial eléctrico contenidas en las ML-I y CIRA se aislaron por la técnica de tubo rodado (Hungate), su selección inicial se basó en la morfología, color y tamaño. Se encontraron formas circulares, puntiformes y rizoides con elevación convexa de borde entero y lobulado de color opaco blanco y opaco blanco con puntos negros al centro (Fig. 4). Se aislaron un total de ocho diferentes colonias a partir de la ML-I y la muestra CIRA, mismas que se probaron en celdas $\mathrm{H}$ para comparar su potencial eléctrico. Estas colonias aisladas (CA) se identificaron como ML-I: CA o MLII: CA, seguido por un número seriado. Las que se aislaron a partir de la muestra CIRA se identificaron como CIRA: CA seguido por un número seriado.

Las bacterias con mejores comportamientos fueron ML-I:CA 6 y CIRA:CA 5 ya que mantuvieron un buen voltaje durante los 20 días. Estas se preservaron e identificaron para futuros experimentos simplemente como ML-I:CA y CIRA:CA (Fig. 5).

\section{Evaluación del potencial de la CEM tipo lote de dos cámaras en forma de cubo}

En la figura 6 se muestra una celda tipo lote de dos cámaras. Este diseño permitió hacer varias mejoras respecto a las celdas $\mathrm{H}$ empleadas previamente, una de las más evidentes fue el remplazo del puente salino por una membrana de intercambio. La longitud del puente es una barrera física que debe ser cubierta por los iones cargados positivamente para llegar al cátodo, lo que disminuye la eficiencia del sistema. La membrana de intercambio catiónico mejora el paso de protones ya que tiene poco menos de $1 \mathrm{~mm}$ de espesor y se encuentra cargada negativamente, lo que

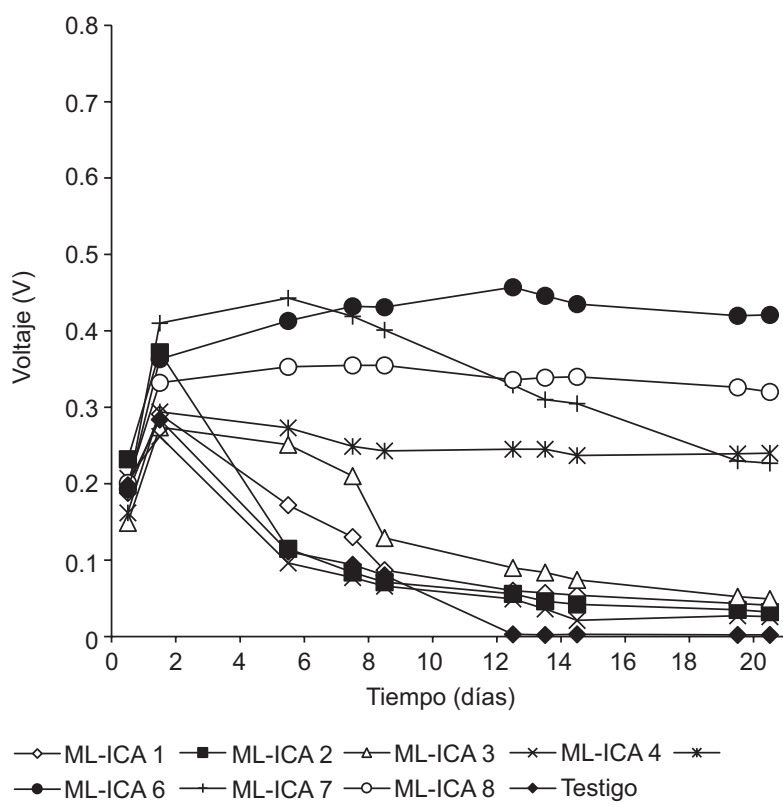

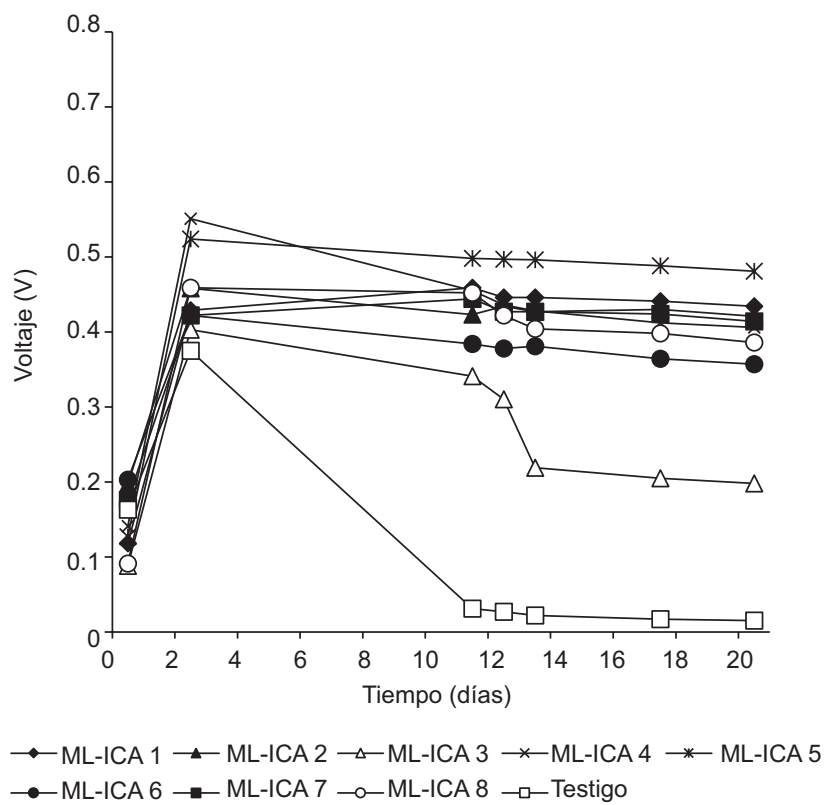

Fig. 5. Promedio del voltaje con respecto al tiempo obtenido en celdas tipo $\mathrm{H}$ de las diferentes colonias aisladas de la muestra Lerma I (A) y muestra CIRA (B) en medio Ravot. $\mathrm{ML}=$ muestra Lerma, CIRA = Centro Interamericano de Recursos del Agua, $\mathrm{CA}=$ Colonia Aislada 
atrae selectivamente a los iones con carga positiva, además de servir como separador entre las cámaras. Las membranas de intercambio iónico trabajan bajo el principio de exclusión de Donnan, que establece que cuando la membrana posee una carga superficial, los solutos con carga opuesta a la de la membrana serán atraídos, mientras que se repelerán los solutos con la misma carga de la membrana (Cuartas 2005). Una buena cantidad de las membranas de intercambio catiónico disponibles comercialmente están formadas por una red de copolímeros que contiene grupos sulfonato cargados negativamente $\left(\mathrm{SO}^{-}\right)$que permiten la transferencia de iones cargados opuestamente, mientras que los iones cargados con la misma polaridad de la membrana se repelen. Tal es el caso de la membrana Ultrex CMI 7000 (Membranes International, EUA) que se usó en estos experimentos (Harnisch et al. 2008). Otro cambio importante fue el del material de los electrodos. Estos deben estar fabricados de un material conductor, biocompatible, químicamente estable y no corrosivo (Logan et al. 2006). Uno de los materiales más empleados es el carbón en diferentes formas (papel, tela, fibra, barra sólida, etc.) ya que es un excelente conductor y de costo relativamente bajo. El uso de tela de grafito permitió tener una mayor área de electrodo, además de facilitar su manejo durante el armado.

En la CEM, la muestra ML-1:CA alcanzó un voltaje máximo de $0.6182 \mathrm{~V}$, cinco días después de montada, mientras que para la muestra CIRA:CA el voltaje más alto fue $0.7378 \mathrm{~V}, 24 \mathrm{~h}$ después de ensamblada y se mantuvo estable a lo largo del monitoreo. Los datos obtenidos indican que los microorganismos provenientes de la muestra CIRA:CA obtuvieron voltajes más altos respecto a los de ML-1:CA (Fig. 6a y b). Cabe mencionar que el muestreo en el río Lerma se realizó en el mes de octubre de 2012, cuando la temporada lluviosa ya había iniciado. Esto puede ser un factor importante ya que el incremento del nivel de agua en esta temporada aumenta la velocidad del río, lo que puede dificultar que se sedimente la materia orgánica. En contraste, las condiciones en las que se encontraban los microorganismos del Centro Interamericano de Recursos del Agua eran menos drásticas, ya que formaban parte de los sedimentos del reactor anaerobio. Esto concuerda con los reportes de Logan (2007) quien menciona que los mejores inóculos de microorganismos provienen de sedimentos que permanecen invariablemente estancados.

Por otra parte y como punto de comparación, se montó otra CEM en las mismas condiciones pero con un inóculo de Geobacter sulfurreducens, que se considera como una de las bacterias exoelectrógenas más eficientes. Con esta bacteria se observa un retardo en la generación de voltaje que se puede asociar al tiempo que tarda $G$. sulfurreducens para formar la biopelícula antes de comenzar a dar voltajes destacables. El voltaje más alto registrado fue de $0.9 \mathrm{~V}$, que se alcanzó aproximadamente 8 días después de que la CEM fue montada (Fig. 6c). Un dato interesante respecto a esta cepa es que se sembró en medios con y sin resazurina y sólo creció en los que tenían este reactivo. Se dice que la resazurina es sólo un colorante que se utiliza como indicador de oxígeno al tornarse a color rosado en el medio (Richardson 2000), pero en este caso los resultados sugieren que $G$. sulfurreducens la utiliza como un aceptor de electrones en reacciones de óxido reducción.

\section{Comportamiento electrógeno de las bacterias}

Una de las características más atractivas de esta tecnología es el producir electricidad, por ende es importante recuperar el mayor número de electrones contenidos en la biomasa como corriente eléctrica, así como obtener la mejor eficiencia en el sistema. Para evaluar estos parámetros en las bacterias recién aisladas se montaron otras CEM de cubo pero en esta ocasión con una solución de nutrientes en la que se controló la cantidad de sustrato (en este caso acetato) para poder evaluar el desempeño de las bacterias recién aisladas. Los resultados se muestran en la figura 7.

\section{Medición del poder}

El poder se midió según la fórmula:

$P=I \cdot V$

donde

$\mathrm{P}=$ potencia eléctrica

$\mathrm{I}=$ corriente en amperios

$\mathrm{V}=$ voltaje

\section{Eficiencia coulómbica}

La recuperación de los electrones, que se refiere a la eficiencia coulómbica, se calcula con la fórmula:

$E c=\frac{C E x}{C T h} \times 100$

donde

Cex $=$ total de coulombios recuperados, que se obtienen integrando la corriente en el tiempo que tardó en consumirse el donador de electrones $\left(\int_{t 0}^{t} d t\right.$.) $\mathrm{C}$ th $=$ coulombios teóricos en el sistema y que a su vez se calculan con: 

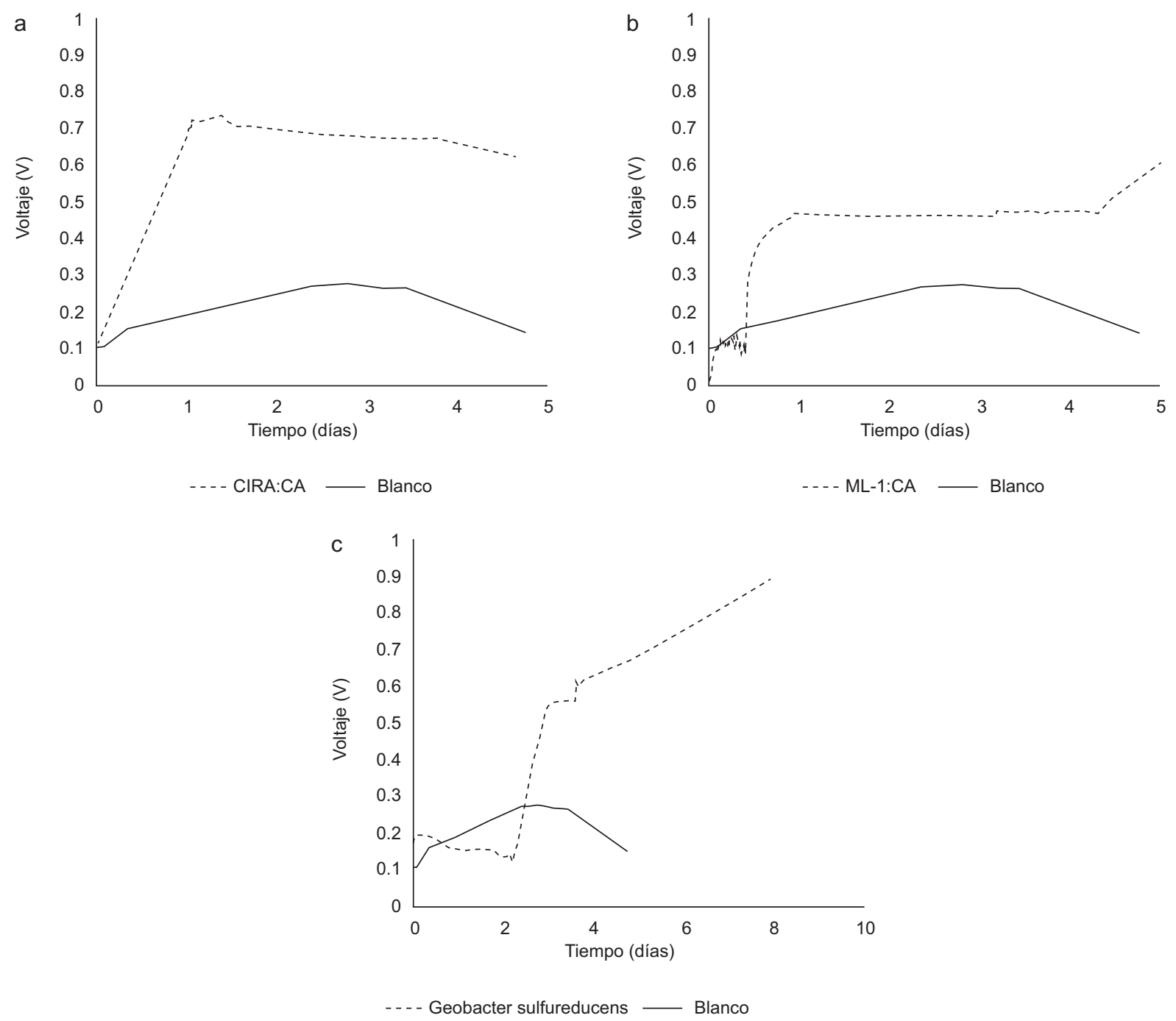

Fig. 6. Generación de voltaje por las diferentes bacterias: a) ML-1:CA, b) CIRA:CA, c) Geobacter sulfurreducens. $\mathrm{ML}=$ muestra Lerma, CIRA = muestra Centro Interamericano de Recursos del Agua, $\mathrm{CA}=$ Colonia Aislada

$C T h=\frac{F \times b \times s \times v}{M}$

donde

$\mathrm{F}=$ constante de Faraday (96 485 C mol-e-),

$\mathrm{b}=$ número de moles de electrones producidos por mol de sustrato (que para el caso del acetato y la glucosa son $8 \mathrm{~mol}-\mathrm{e}-/ \mathrm{mol}$ y $24 \mathrm{~mol}-\mathrm{e}-/ \mathrm{mol}$, respectivamente),

$\mathrm{M}=$ concentración molar del sustrato utilizado $\mathrm{v}=$ volumen del líquido

Dado que para este estudio se empleó acetato como sustrato donador de electrones, se utilizó como reacción de referencia la oxidación completa de este compuesto:
Oxidación del acetato: $\mathrm{CH}_{3} \mathrm{COOH}+2 \mathrm{H}_{2} \mathrm{O}=>2$ $\mathrm{CO}_{2}+8 \mathrm{H}++8 \mathrm{e}^{-}$

De acuerdo con ello, la oxidación de $1 \mathrm{~mol}$ de acetato produce $8 \mathrm{~mol}$ de electrones $(1 \mathrm{~mol}$ de acetato $=8 \mathrm{~mol}-\mathrm{e}^{-} / \mathrm{mol}$; Kim et al. 2011).

La muestra ML-1:CA obtuvo una potencia máxima de $0.02118 \mathrm{~mW} / \mathrm{cm}^{2}$ y con un promedio de $0.01137 \mathrm{~mW} / \mathrm{cm}^{2}$ tras los cinco días que tardó en consumirse el acetato (Fig. 7a). Por otro lado, la muestra CIRA:CA alcanzó un valor máximo de potencia de $0.02142 \mathrm{~mW} / \mathrm{cm}^{2}$, mismo que se alcanzó tras 5.5 días de incubación y con un promedio de $0.01217 \mathrm{~mW} / \mathrm{cm}^{2}$ tras 6.26 días que tardó en consumirse el acetato (Fig. 7b). 

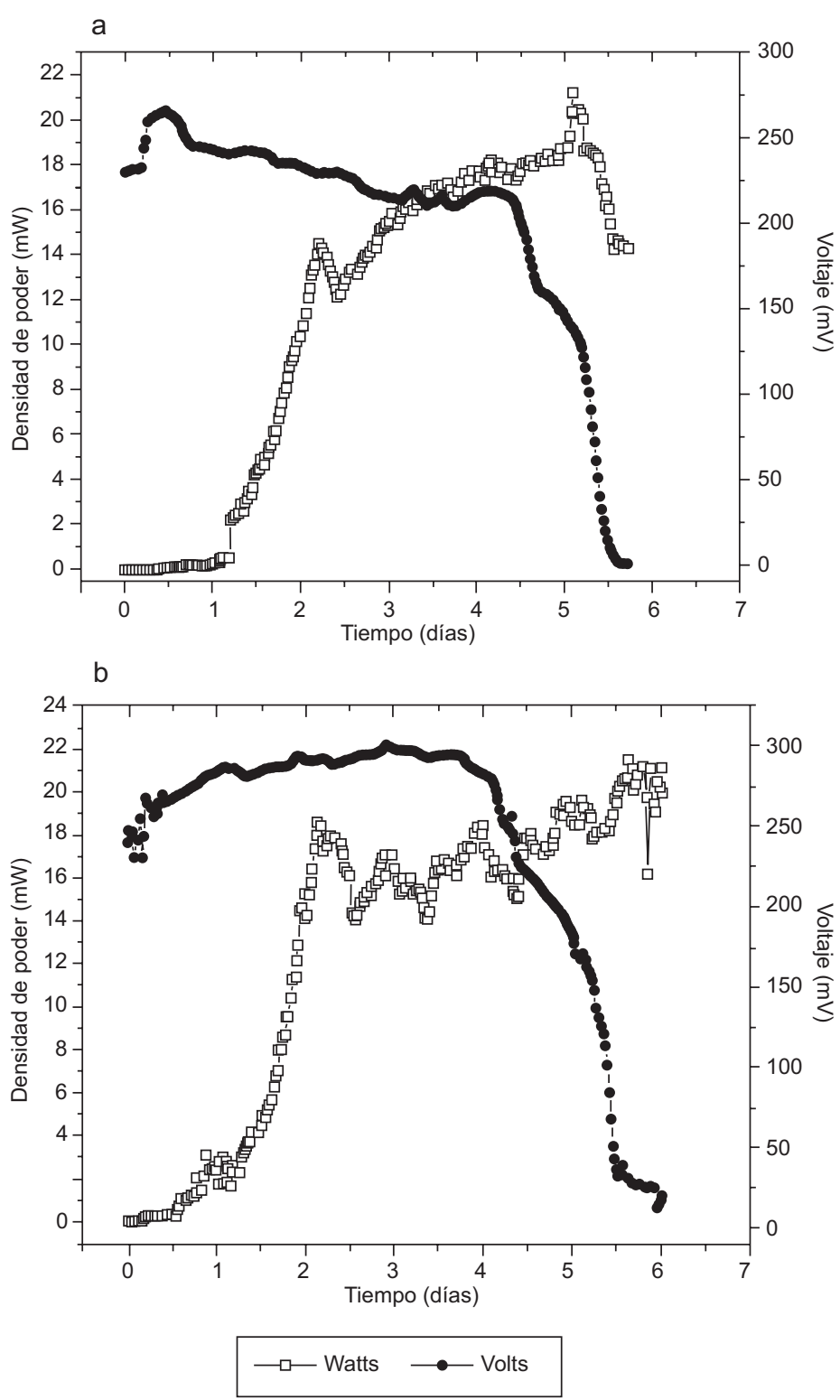

Fig. 7. Voltaje y potencia alcanzados por las muestra en solución de nutrientes utilizando acetato como donador de electrones a una concentración de $0.5 \mathrm{mM}$. a) ML-1:CA, b) CIRA:CA. ML = muestra Lerma, CIRA = muestra Centro Interamericano de Recursos del Agua, $\mathrm{CA}=$ Colonia Aislada

Los voltajes máximos producidos por las muestras ML-I:CA y CIRA:CA en estas condiciones fueron en promedio de $203 \mathrm{mV}$ y $236.85 \mathrm{mV}$, respectivamente, similares a lo reportado anteriormente (330 mV y $324 \mathrm{mV}$ ) en experimentos donde se usó un sistema parecido con inóculos provenientes de sedimentos de aguas residuales (Oh et al. 2004, Logan et al. 2006).

\section{Eficiencia coulómbica}

Con los datos de corriente se realizó su integración en función del tiempo. Se obtuvo 24233.07 C para ML-1:CA y 24431.97 C para CIRA:CA, con lo que se calculó la eficiencia al aplicar la ecuación 2 a partir de los cálculos de coulombios teóricos obtenidos por la ecuación 3, donde se sustituyó como sigue: $\mathrm{F}$ es la constante de Faraday (96 485 C mol-e-), b es 
el número de moles de electrones producidos por mol de sustrato ( 8 mol-e-/mol para acetato), s es la concentración del sustrato $(0.0295 \mathrm{~g} / \mathrm{L}), \mathrm{v}$ es el volumen del líquido de la cámara anaerobia $(0.1$ L) y $\mathrm{M}$ es el peso molecular del sustrato empleado (acetato: $60 \mathrm{~g} / \mathrm{mol}$ ).

La eficiencia coulómbica obtenida fue similar en ambas muestras con un $64 \%$ aproximadamente, valor situado en un rango de bueno a muy bueno de acuerdo con Logan (2007). Experimentos similares realizados por Oh et al. (2004), con un inóculo proveniente de lodos de una planta de tratamiento y acetato como donador de electrones, reportaron eficiencias de $71 \%$, mientras que Bennetto (1990) obtuvo alrededor de $80 \%$ con Escherichia coli y glucosa, aunque las áreas de la membrana de intercambio fueron mayores que las empleadas en este estudio. En otro estudio realizado por Chaudhuri y Lovely (2003) utilizaron consorcios provenientes de lodos de una planta tratadora y glucosa como donador de electrones y obtuvieron eficiencias de hasta $83 \%$.

\section{Identificación de especies}

Se obtuvieron secuencias consenso de 1212 y 1215 pares de bases del ARN ribosomal 16S de las cepas
ML-I:CA 6 y CIRA:CA 5, que al ser comparadas con las secuencias depositadas en el GenBank a través del programa Blast, ambas presentaron $98 \%$ de semejanza con Clostridium sordellii ATCC9714 y Clostridium bifermentans ATCC638, respectivamente. Este resultado es interesante, ya que se han reportado diversas especies del género Clostridium capaces de generar electricidad (Khan 2009). Además, cabe mencionar que a pesar de que hasta el momento no hay reportes referentes a la generación de electricidad con Clostridium bifermentans, sí se ha utilizado en la producción de hidrógeno (Wang et al. 2003).

A pesar de haber aislado colonias a partir de las muestras era probable que en éstas se encontrara más de una especie formando un consorcio. Para conocer si las colonias albergaban a más de un tipo bacteriano y ayudar a la identificación de las mismas, se decidió observar las muestras con la ayuda de un microscopio electrónico. Las imágenes muestran un sólo tipo bacteriano en cada cultivo y la morfología corresponde a lo esperado de acuerdo con la identificación por métodos moleculares (Fig. 8).

Como se dijo anteriormente, ya se han identificado diversos grupos de bacterias capaces de generar electricidad en una CEM, entre las que se
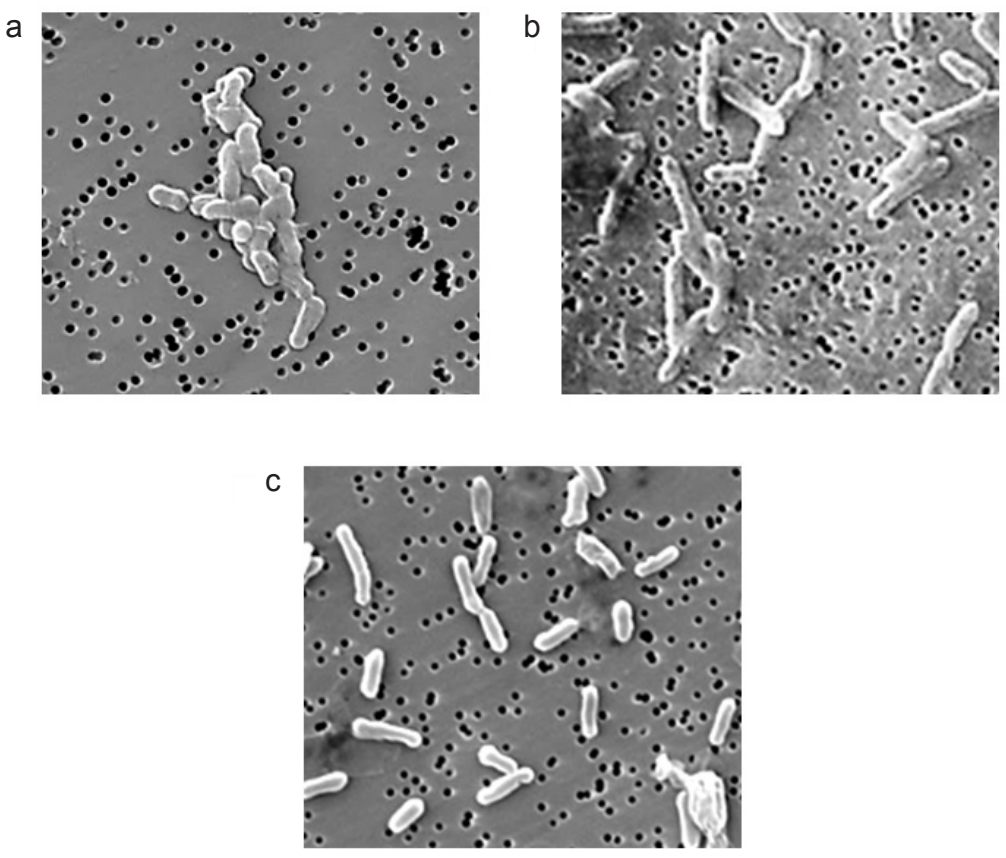

Fig. 8. Microfotografías de los microorganismos: a) CIRA:CA (Clostridium bifermentans), b) ML-1:CA (Clostridium sordellii), c) Geobacter sulfurreducens. $\mathrm{ML}=$ muestra Lerma, CIRA $=$ muestra Centro Interamericano de Recursos del Agua, CA = Colonia Aislada 
encuentran algunas especies de los géneros Rhodoferax, Shewanella, Pseudomonas, Aeromonas, Geobacter, Geopsychrobacter, Desulfuromonas, Clostridium y Geothrix (Logan 2009). Sin embargo, normalmente el aislamiento de este tipo de organismos se ha hecho por medio de técnicas convencionales de siembra en placa, lo que impide seleccionar aquellas bacterias con actividad exoelectrogénica y, por tanto, dificulta la recuperación de organismos para pruebas futuras. El uso de dos tipos distintos de CEM permite seleccionar desde los primeros experimentos aquellos especímenes con mejores perspectivas para la generación de electricidad, lo que agiliza el aislamiento e identificación de éstos (Zuo et al. 2008).

\section{CONCLUSIONES}

Del muestreo de los sedimentos del río Lerma y del lodo del reactor anaerobio del CIRA se aislaron diferentes colonias bacterianas que probaron ser exoelectrógenas en celdas tipo $\mathrm{H}$ con puente de agar salino y de ellas se eligieron las que mostraron mejor desempeño en la generación de electricidad.

A cada colonia aislada se le midió su potencial eléctrico en celdas tipo $\mathrm{H}$. Basados en los voltajes más altos a lo largo del experimento, se seleccionó para la muestra ML-I, la colonia identificada como ML-I:CA 6 y para la muestra CIRA la colonia identificada como CIRA:CA 5, que obtuvieron voltajes de 0.401 y $0.440 \mathrm{~V}$, respectivamente (medidos en circuito abierto).

Con el fin de favorecer la producción eléctrica se construyó una celda de energía microbiana tipo lote en forma de cubo con dos cámaras, cada cámara con un volumen de $110 \mathrm{~cm}^{3}$, en la que se implementaron nuevos materiales como la tela de grafito (electrodos) y membrana de intercambio iónico.

El uso de dos tipos distintos de CEM permitió el aislamiento e identificación de dos especies de bacterias (Clostridium sordellii y Clostridium bifermentans) las cuales no habían sido reportadas anteriormente como exoelectrógenas.

\section{AGRADECIMIENTOS}

Los autores agradecen a la Dra. Katy Juárez del Instituto de Biotecnología de la Universidad Nacional Autónoma de México, por habernos facilitado la bacteria Geobacter sulfurreducens y por todo el apoyo que nos brindó a lo largo de este trabajo. Agradecen también al Técnico Jorge Pérez del Prado por la ayuda para la obtención de las microfotografías, al personal del taller de vidrio y al de talleres generales del Instituto Nacional de Investigaciones Nucleares por la construcción de las distintas celdas de energía microbiana.

\section{REFERENCIAS}

Altschul S.F., Madden T.L., Schäffer A.A., Zhang J., Zhang Z., Miller W. y Lipman D.J. (1997). Gapped BLAST and PSI-BLAST: a new generation of protein database search programs. Nucleic Acids Res. 25 (17), 33893402. DOI: $10.1093 / \mathrm{nar} / 25.17 .3389$

Benavides L.M.J., Quintero G., Guevara V.A.L., Jaimes C.D.C., Gutiérrez R.S.M. y Miranda G.J. (2006). Bioremediación de suelos contaminados con hidrocarburos derivados del petróleo. NOVA-Publicación Científica 4 (5), 82-90

Bennetto H. (1990). "Bugpower" - the generation of microbial electricity. En: Frontiers of science. (A. Scott, Ed.), Blackwell, Oxford, Reino Unido, pp. 60-82.

Chaudhuri S. y Lovely D. (2003). Electricity generation by direct oxidation of glucose in mediator less microbial fuel cells. Nat. Biotechnol. 21 (10), 1129-1232.

DOI: $10.1038 / \mathrm{nbt} 867$

Cuartas U. (2005). Estudio del proceso de nanofiltración para la desmineralización de lactosuero dulce. Tesis de Doctorado. Universidad Politécnica de Valencia, España, 308 pp.

Esteve-Núñez A., Sosnik J., Visconti P. y Lovley R. (2008). Fluorescent properties of c-type cytochromes reveal their potential role as an extracytoplasmic electron sink in Geobacter sulfurreducens. Environ. Microbiol. 10 (2), 497-505.

DOI: $10.1111 / \mathrm{j} .1462-2920.2007 .01470 . \mathrm{x}$

Estrada A.E.B. y Salazar O.M.S. (2013). Generación de energía eléctrica a partir del tratamiento de aguas residuales por medio de bioceldas. Coordinación de Tratamiento y Calidad del Agua. Instituto Mexicano de Tecnología del Agua. Informe final. TC1314.1., 81 pp.

Falcón A., Lozano E. y Juárez K. (2009). Bioelectricidad. Biotecnología 13, 62-78.

Harnisch F., Schröder U. y Scholz F. (2008). The suitability of monopolar and bipolar ion exchange membranes as separators for biological fuel cells. Environ. Sci. Technol. 42 (5), 1740-1746. DOI: 10.1021/es702224a

He Z., Minteer S. y Angenent L. (2005). Electricity generation from artificial wastewater using an upflow microbial fuel cell. Environ. Sci. Technol. 39 (14), 35262-5267. DOI: $10.1021 / \mathrm{es} 0502876$

Khan A. (2009). Electricity generation by microbial fuel cells. Adv. In Nat. Appl. Sci. 3 (2), 279-286. 
Kim I.S., Chae K.J., Choi M.J. y Verstraete W. (2008). Microbial fuel cells: Recent advances, bacterial communities and application beyond electricity generation. Environ. Eng. Res. 13 (2), 51-65.

DOI: 10.4491/eer.2008.13.2.051

Kim K., Chae K., Choi M., Ajayi F., Jang A., Kim C. y Kim I. (2011). Enhanced coulombic efficiency in glucose-fed microbial fuel cells by reducing metabolite electron losses using dual-anode electrodes. Bioresour. Technol. 102 (5), 4144-4149.

DOI: 10.1016/j.biortech.2010.12.036

Lewis N.S. y Nocera D.G. (2006) Powering the planet: Chemical challenges in solar energy utilization. P. Natl. Acad. Sci. USA 103 (43), 15729-15735. DOI: 10.1073/pnas.0603395103

Logan E., Hamelers B., Rozendal R., Schroder U., Keller J., Freguia S., Aelterman P., Verstraete W. y Rabaey K. (2006). Microbial fuel cells: Methodology and technology. Environ. Sci. Technol. 40 (17), 5181-5192. DOI: $10.1021 / \mathrm{es} 0605016$

Logan E. (2007). Microbial fuel cells. Wiley-Interscience, Pennsylvania, EUA, 199 pp.

DOI: $10.1002 / 9780470258590$

Logan E. (2009). Exoelectrogenic bacteria that power microbial fuel cells. Nat. Rev. Microbiol. 7 (5), 375381. DOI: $10.1038 /$ nrmicro2113

Marzan L.W., Hossain M., Mina S.A., Akter Y. y Chowdhury A.M. (2017). Isolation and biochemical characterization of heavy-metal resistant bacteria from tannery effluent in Chittagong city, Bangladesh: Bioremediation viewpoint. Egypt. J. Aquat. Res. 42 (1), 65-74 pp. DOI: 10.1016/j.ejar.2016.11.002
Oh S., Min B. y Logan B. (2004). Cathode performance as a factor in electricity generation in microbial fuel cells. Environ. Sci. Technol. 38 (18), 4900-4904.

DOI: $10.1021 / \mathrm{es} 049422 \mathrm{p}$

Ravot G., Ollivier B., Magot M., Patel B., Crolet J., Fardeau M. y Garcia J. (1995). Thiosulfate reduction, an important physiological feature shared by members of the order thermotogales. Appl. Environ. Microbiol. 61 (5), 2053-2055.

Richardson D.J. (2000). Bacterial respiration: A flexible process for a changing environment. Microbiology, 146 (3), 551-571.

DOI: 10.1099/00221287-146-3-551

Vázquez-Nin G. y Echeverría O. (2000). Introducción a la microscopia electrónica aplicada a las ciencias biológicas. Fondo de Cultura Económica, México, 167 pp.

Wang C.C., Chang C.W., Chu C.P., Lee D.J., Chang B.V.y Liao C. S. (2003). Producing hydrogen from wastewater sludge by Clostridium bifermentans. J. Biotechnol. $102(1), 83-92$.

DOI: $10.1016 / \mathrm{S} 0168-1656(03) 00007-5$

Zhang Z., Schwartz S., Wagner L. y Miller W. (2000). A greedy algorithm for aligning DNA sequences. J. Comp. Biol. 7 (1-2), 203-214. DOI: $10.1089 / 10665270050081478$

Zuo Y., Xing D., Regan J. M. y Logan B. E. (2008). Isolation of the exoelectrogenic bacterium Ochrobactrum anthropi YZ-1 by using a U-tube microbial fuel cell. Appl. Environ. Microbiol. 74 (10), 3130-3137.

DOI: 10.1128/AEM.02732-07 